\title{
Modeling of managerial processes in the conditions of innovative economy
}

\author{
Zhanna Yuryevna Dankova \\ Department of sociology and management \\ Belgorod State Technological University named after \\ V.G. Shukhov \\ Belgorod, Russia \\ zdankova@yandex.ru
}

\author{
Elena Sergeevna Muzyleva \\ Department of sociology and management \\ Belgorod State Technological University named after \\ V.G. Shukhov \\ Belgorod, Russia \\ helen10000@mail.ru
}

\begin{abstract}
The article examines the trends in the development of business processes regulation in Russian companies. At the present stage of the formation of a market economy in Russia, in the conditions of large-scale structural reorganization of the country's economy as a whole, the description and regulation of business processes of the company as a whole, and business processes in particular, is of major importance. In this regard, the trend towards innovative activity in the field of description and regulation of business processes is gaining popularity. But as shown by the analysis carried out by the authors, most aspects of the regulation of business processes have not been studied either on the theoretical or on the empirical levels. Therefore, the authors presented a model for regulating business processes, which can be used in the practice of companies of any sector of the economy. In addition, the proposed ways to introduce the regulation of business processes in the practical activities of companies.
\end{abstract}

Keywords- business process, regulation, regulation of business processes, modeling, economy.

The current stage of development of Russian society actualizes the task of training highly qualified personnel in all spheres of national economy, capable of solving problematic issues of varying complexity [2]. The content of this kind of work requires, first of all, the possession of organizational and technological skills in managing the procedural and functional aspects of the activity. At the same time, the degree of regulation and regulation of the entire work process has a significant role in the success of the final results. However, at present, questions concerning the development of the theory and practice of regulation in comparison with the Soviet period of the administrative-command economy have lost relevance. So there is an obsolescence of methodical and technological developments, the tariff-qualifying directories of works and professions are practically not updated, labor standards for performing various functions are not updated.

Nevertheless, more and more often at the state level there is an objective need for the revival and development of the regulation of labor. Moreover, the positive experience of organizing the activities of Western companies in most European countries is an interrelated, purposeful set of regulated business processes.

In Russia, theoretical approaches and empirical tools for building a regulatory system in general are just beginning to be developed. The main problem in building the company's business processes and their regulation is the lack of both theoretical and methodological tools: there are no clear definitions of the basic concepts, methods and schemes of implementation. While it has long been proven that the regulation of labor is an effective tool for managing the company. The existing normative documents in the sphere of regulation and rationing of the organization's activities are not relevant now, and no work is being done to update them. Commercial companies, on the other hand, invest in the creation of their own sets of documents in the field of regulating the activities of employees. If in the Soviet times the work of employees in the organization was regulated in most cases, now one of the main directions is the regulation of the company's business processes in general, in our country this is not yet formed direction, but a kind of trend that is becoming more popular.

In addition, in many companies, especially not large, the regulation of labor remains at a formal level. Although the organizations are developing sets of normative and methodological documents in the field of business process regulation, they are never implemented in practice [3]. Often, a formal approach to regulation leads to the creation of a mass of people who do not work in practice and do not need documents. In this regard, theoretical and practical developments in the field of labor regulation are becoming more and more in demand and relevant.

The modern process approach regards the organization as a single well coordinated mechanism. From the point of view of this approach, in any company there are various business processes that have at the input any resources (material, human, technical and others), and at the output they receive a certain result (finished product, service, document).

Business processes are the foundation for the organization to achieve success and achieve the goals set on all planning horizons. At present, organizational design specialists formulate slightly different definitions of the term "business process". In our opinion, the most accurately reflects the 
specifics of business processes is the definition proposed by M. Hammer and D. Champi, who understand the business process as a set of different types of activities, within which "at the entrance" one or more types of resources are used, and as a result of this "output" creates a product that represents value for the consumer [6].

All business processes of the company can be classified into four groups. Let us consider them in more detail.

1. The main business processes of the company are the processes that create the added value of the company, that is, making profit, producing a product or services, satisfying the needs of customers, and have a strategic focus. Their distinctive feature is that they determine the direction of the organization and bring the main income.

2. Providing business processes are processes that support the organization's infrastructure. This type of processes can include administrative and economic support, security, legal support

3. Business development processes are investment activities, where the result is achieved after a certain period. Most often, these processes include various projects.

4. Business management processes are related to the supporting processes, but they are aimed at maintaining the competitiveness and development of the organization, as well as regulating its current activities. Their immediate goal is to manage the activities of the organization. Business management processes have a typical structure, which is a standard chain of management cycle, which consists of the following stages:

- Planning. At this stage, information is collected and analyzed, and a plan for further action is being developed.

- Organization. Completion of the planning stage is the developed plan. Further it is necessary to ensure its implementation - to bring activities to the staff, to motivate and provide employees with the resources necessary.

- Monitoring. After the expiration of the established period, it is necessary to gather factual information about the implementation of the planned work and the results achieved.

Control. After the accounting is taken, the plan is compared with the actual information and the deviations of the actual indicators from the planned ones are analyzed.

- Coordination. At the last fifth stage, a decision is taken on the next steps - adjusting the plans, stimulating or discouraging the staff involved in the process.

Business management processes are related to the supporting processes, but they are aimed at maintaining the competitiveness and development of the organization, as well as regulating its current activities. Their immediate goal is to manage the activities of the organization. But, the increase in efficiency from the management of the organization on the basis of the process approach is achieved in conjunction with the regulation of the described processes.

Under the regulation of business processes is understood the development of regulatory and methodological documents that partially or completely establish the procedure for managing and implementing the business process, as well as the requirements for the resources necessary for their implementation.

Depending on the stage of the life cycle of the organization, the level of regulation of staff's work also depends. Consider the model of the life cycle of Adizes, in the context of the development of the regulation of labor in the organization (Fig.1).

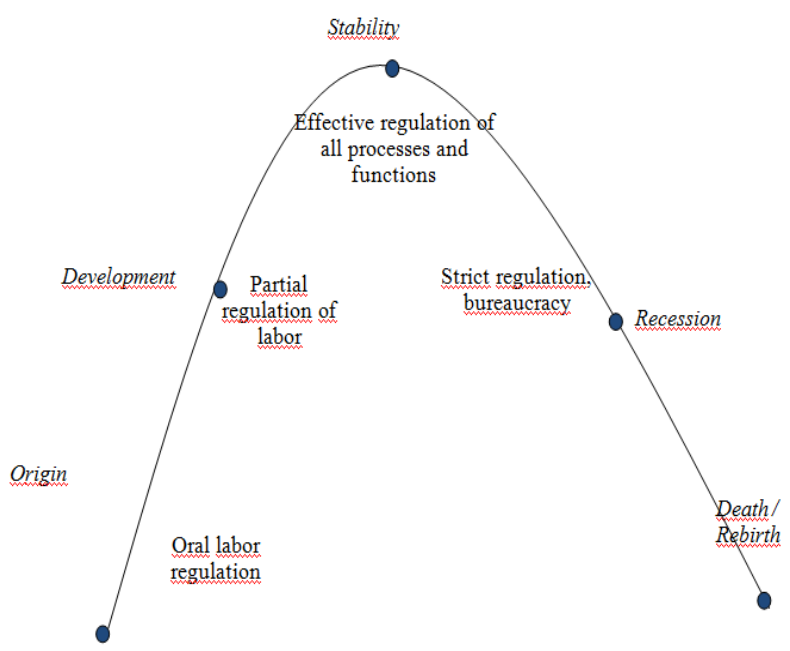

Fig.1. Simplified model of the organization's life cycle

The first stage is the stage of the origin of the organization. It is characterized by the implementation of the idea of creating a company in life and the beginning of its development. Most of the staff of the organization at this stage does not exceed 15 people. The management structure is linear, there is no clear division of responsibilities and responsibilities. The main document regulating the duties of personnel is the labor contract. In addition, the coordination of the activities of the subjects of management is carried out verbally by the head of the company who solely takes all decisions.

The second stage is the stage of development. With the successful development of the company and the increase in the number of employees, there is a hierarchical structuring of management and a functional division of labor. Functional units are being formed. In this regard, there is a need to create Regulations on structural divisions and job descriptions. Thus, the regulation of labor from the oral to the documented form.

The third stage is maturity. The company has identified and documented all the processes being implemented and each structural unit is responsible for achieving concrete results and for a clear smooth implementation of the process as a whole. The system of indicators of productivity and labor efficiency has been formed, their constant monitoring is being carried out, and responsibility is distributed among all subjects of management. Documented and regulated all business processes, developed a functional link between the heads of structural units. Clear regulations have been developed that describe the actions of personnel in a given situation, which are constantly updated. This stage for the organization is the most economically profitable, because due to the optimal regulation of all processes, the number of errors and crisis situations is reduced.

The fourth stage is a decline. All processes in the company are strictly regulated. Managers do not make efforts 
to change processes (they do not organize the process, do not allocate resources, do not train employees, do not control compliance with the requirements of the regulations when executing the process, etc.). The developed regulations are not adjusted, which leads to a lack of necessary resources and inefficient activities. What further leads to the final stage - the death of the organization.

Переводчик Google для бизнеса-Инструменты переводчикаПереводчик сайтов

The advantage of regulating business processes is undeniable. Firstly, the regulatory documents formally fix for a certain period the issues of subordination between, the distribution of responsibility, the order of interactions, the document flow and other aspects of achieving effective performance.

Secondly, the regulations are the main tool of the head, allowing him to organize the effective work of the unit with minimal interference in his activities, in turn, the employees of the unit, using regulations, will be able to effectively carry out more work without agreement with the manager. For this it is necessary to develop mechanisms for monitoring the implementation of these regulations.

Thirdly, with the introduction of regulations, the responsibility of employees for the functions and tasks that are being implemented is increased, which increases the productivity of both physical and mental labor. In addition, the regulations increase the transparency of the employee's activities and allow for an individual assessment of his labor contribution.

Fourth, the regulations ensure transparency of the organization as a whole, which makes it possible to manage organization more effectively, improve it and monitoring and control it.

Fifthly, regulation is the basis for implementing process management, by developing and introducing process regulations.

The regulatory and methodological documentations for the regulation of business processes of the organization are developed at three levels: the management processes of the organization as a whole, the level of processes and units, the level of operations and employees. This model enables the company to implement normative and methodological documentation regulating both private processes and common for the whole organization. In addition, it allows to structure local regulations of the company and stage-by-stage to plan their development and implementation in practice.

Regulating processes at the level of the organization as a whole means creating a set of interrelated documents that determine both management processes and processes, rules, policies common to the entire organization. This group includes such documents as the Charter, the Collective Agreement, Staff Schedule, Management Process Cards, Company Staff Regulations, Company Structure Chart, Company Workflow Scheme, Organization Business Process Summary Chart, Organization Management Regulations

At the next level of the company's processes and divisions, documents are being developed that regulate the specific processes of the company and the activities of its structural units. These include: the rules for the implementation of processes (both cross-cutting or inter- functional, and localized within the unit), regulations on divisions; operograms and process document documents, function distribution matrixes in the subdivision, schemes of functional interrelations of the subdivision.

The level of operations and staff includes development of the following documents: job descriptions of employees, employee work instructions, personal specifications, workplace models, operating rules of processes (both through and in one department).

In addition, the body of documents regulating business processes could be divided into structural and process regulations. The first regulate the company's activities in terms of organizational structure - they first describe the company's structural units, and then specify the functions that they do. The second regulate the specific business processes of the organization. In these regulations, unlike structural ones, processes are first described, and then structural links that do these processes (Figure 2). Examples of process regulations at different levels of management are:

- Regulations on intra-company activities, which total regulates all activities of the organization;

- Standing order of business process, function and procedure. These provisions have been interrelated since the function is part of the process and the procedure, respectively is part of the function. Therefore, the function provision documentary determines a certain part of the process and the procedure clause specifies the narrow part of the function.

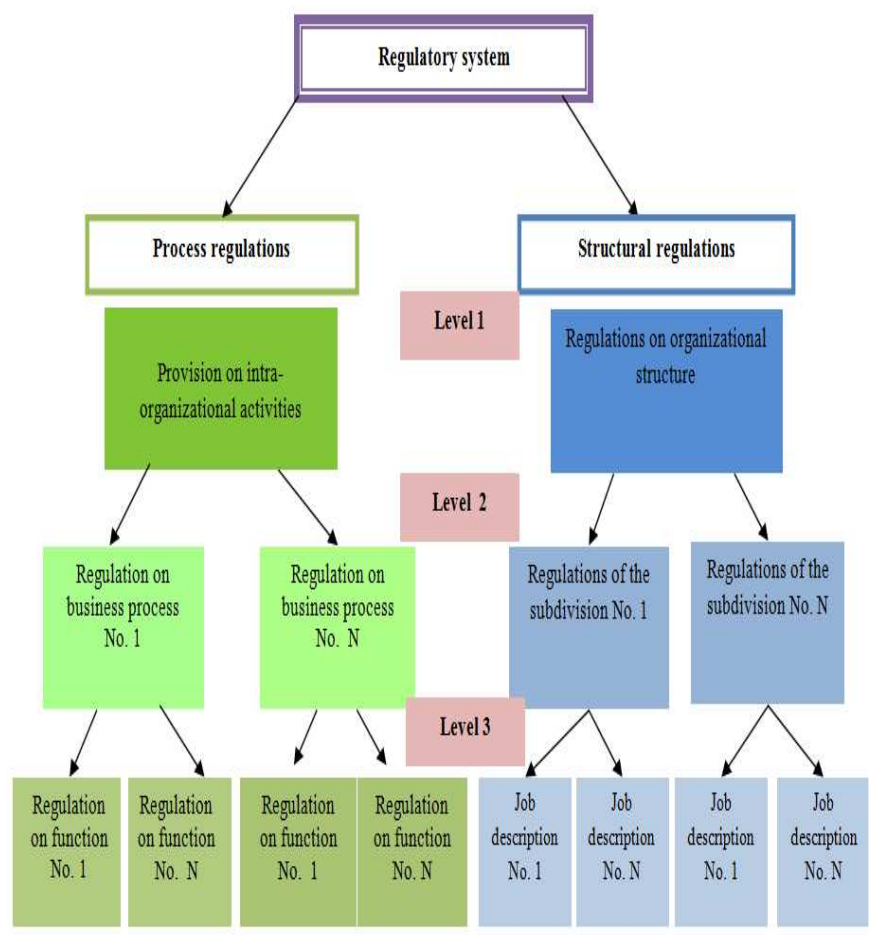

Fig.2. System for regulating business processes of the organization

To study the degree of application of the process approach to management, as well as the development of the company's business processes and their regulation, the authors conducted a survey of Belgorod region companies 
engaged in wholesale and retail trade. The following indicators were identified for evaluation:

1. Presence of the described schemes of business processes;

2. Availability of documents on the regulation of labor;

3. Level of development of normative and methodical documentation

4. Provision of specialists in the field of modeling and regulation of business processes;

5. Degree of automation of labor of personnel

A ten-point scale was used for assessment, where 10 is an ideal state, and 1 is an unsatisfactory state. The averaged values were ranked using the priority ranking method. Indicator that the regulation of business processes in the field of personnel management is carried out at the appropriate level and all the necessary regulatory documents have been developed, we will consider a score of 10 points. The results are shown in Table 1.

\section{TABLE I. EVALUATION RESULTS}

\begin{tabular}{|c|c|c|c|c|}
\hline $\begin{array}{c}\text { Indicator } \\
\text { name }\end{array}$ & $\begin{array}{c}\text { Score of } \\
\text { the } \\
\text { indicator }\end{array}$ & Weight & $\begin{array}{l}\text { Weighted } \\
\text { estimate }\end{array}$ & Relevance \\
\hline $\begin{array}{l}\text { Presence of } \\
\text { the described } \\
\text { schemes of } \\
\text { business } \\
\text { processes }\end{array}$ & 1 & 0,3 & 0,3 & 0,28 \\
\hline $\begin{array}{l}\text { Availability of } \\
\text { documents on } \\
\text { the regulation } \\
\text { of labor }\end{array}$ & 3 & 0,4 & 1,2 & 0,35 \\
\hline $\begin{array}{l}\text { Level of } \\
\text { development } \\
\text { of normative } \\
\text { and } \\
\text { methodical } \\
\text { documentation }\end{array}$ & 4 & 0,3 & 1,2 & 0,35 \\
\hline $\begin{array}{l}\text { Provision of } \\
\text { specialists in } \\
\text { the field of } \\
\text { modeling and } \\
\text { regulation of } \\
\text { business } \\
\text { processes }\end{array}$ & 2 & 0,2 & 0,4 & 0,21 \\
\hline $\begin{array}{l}\text { Degree of } \\
\text { labor } \\
\text { automation }\end{array}$ & 5 & 0,1 & 0,5 & 0,14 \\
\hline Total & & 1 & 3,6 & 1 \\
\hline
\end{tabular}

According to the weighted estimate, the most important indicators in the regulation of business processes are: the availability of labor regulations (0.35); the degree of elaboration and updating of the set of normative and methodological documents $(0.35)$ and the availability of the described business process diagrams (0.28). It is worth noting that it is these parameters that the company received the lowest scores. Thus, the most significant for the company indicators were unsatisfactory, indicating that there are a number of problems in the regulation of personnel. We will reflect the results obtained with the help of a lobed diagram for a more vivid presentation of , (Fig. 3)

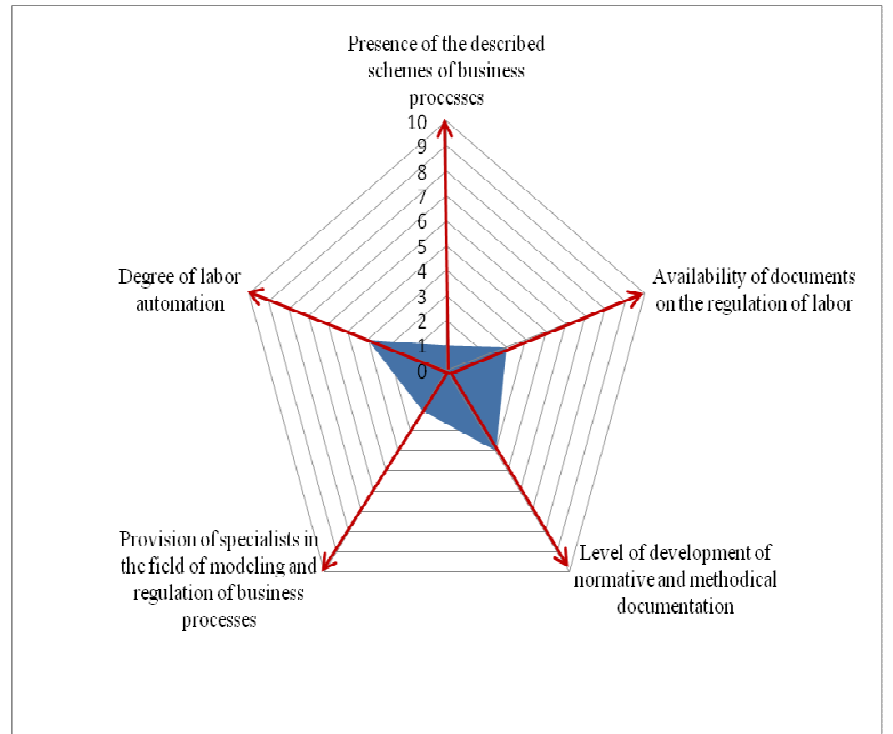

Fig. 3. Results of the analysis of business processes regulation using the "Quality Rose" method

Based on the received schedule, we can say that the indicators of the existence of the developed and effectively implemented regulation of business processes in the personnel management system in companies were the highest scores for all the selected parameters. But, based on the analysis, we received that all scores are extremely low, ranging from 1 to 5 , which indicates that there is no activity to regulate business processes in the field of personnel management.

In addition, we have analyzed the ratio of remuneration of company personnel and revenues. This indicator is the main indicator of the effectiveness and productivity of the organization. According to research, on average in Russian companies this figure is in the range of $11-15 \%$, while in Europe this indicator is 2-2.5 times higher. In the companies surveyed, the average is $10 \%$ (Figure 4 ).

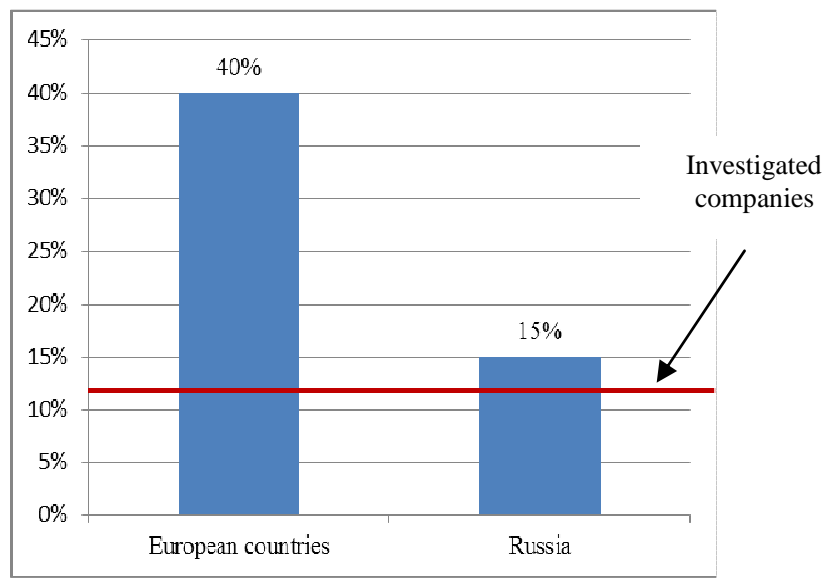

Fig.4. Comparison of the ratio of remuneration of company personnel and revenues

As can be seen from the figure, the companies surveyed in terms of performance are lower than in the whole country, which shows a low return on staff performance. In our opinion, this fact is related to the non-transparency of 
the company's management system and the lack of regulation of activities and the introduction of the description and regulation of business processes, in turn, will increase the productivity of employees and, consequently, increase the productivity and productivity of the organization.

In addition, the obtained extremely low results of the research, in our opinion, are related to the fact that at the moment there is no single model for regulating business processes. This model should take into account all aspects of the regulation of labor and modeling of business processes. In this regard, we have developed an author's model for regulating the business processes of the organization, which is presented in Figure 5.

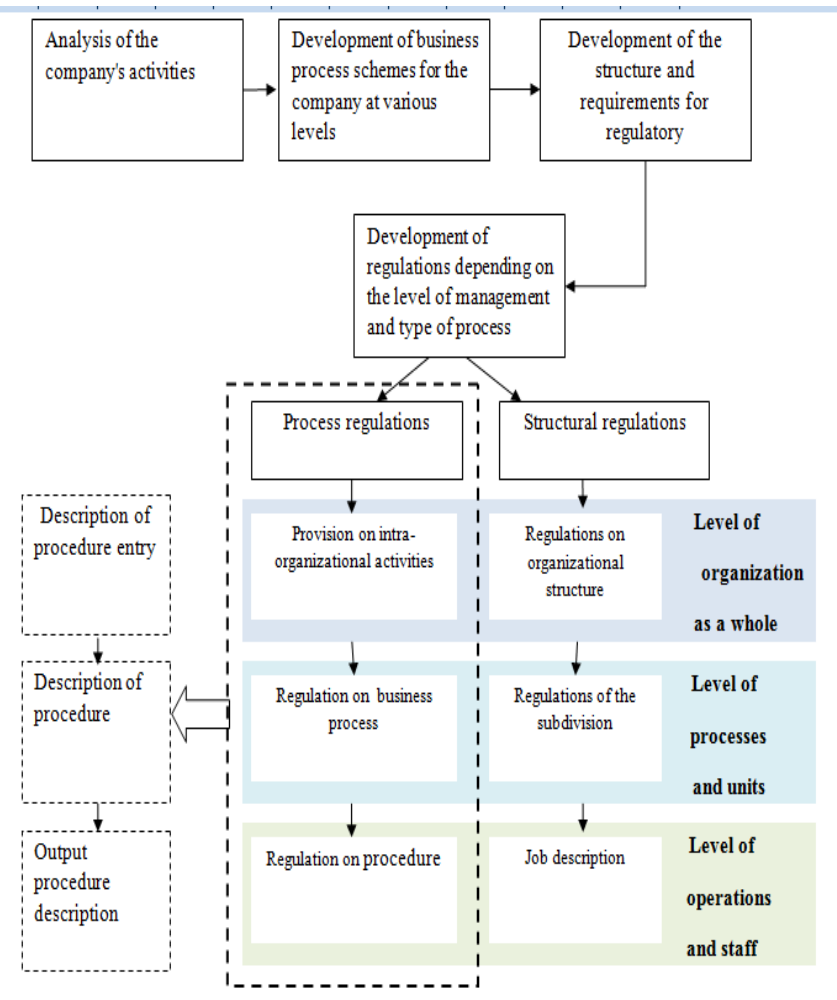

Fig.5. Model of regulation of business processes of the company

In addition to the presented model, the authors developed a number of principles on the basis of which the presented model should be implemented. Let's consider these principles in more detail:

1. Objectivity - is that it is necessary to take into account external and internal factors when regulating business processes, and also to be guided in their description by statistically reliable data.

2. Measurability - Indicators and indicators of evaluation should be developed for each process.

3. Proportionality - the smaller the inputs and outputs, the better the process. The number of process inputs can not be more than one, and the number of outputs - no more than two or three.

4. Rationality - the description of the business process should not include duplicate and / or unjustified actions.
The implementation of an action in the business process must be mathematically and analytically justified.

5. Structure optimality - the structure of the business process should not include more than 7-10 actions and 3-4 events.

The presented model is a decomposition of works on the regulation of business processes of the company, we will consider each of the blocks in more detail.

Block 1. Analysis of current activities of the company. In order to describe the management processes, it is necessary to obtain information about the activities of the structural unit. Figure 6 shows the algorithm for determining the processes of sub-unit of the organization.

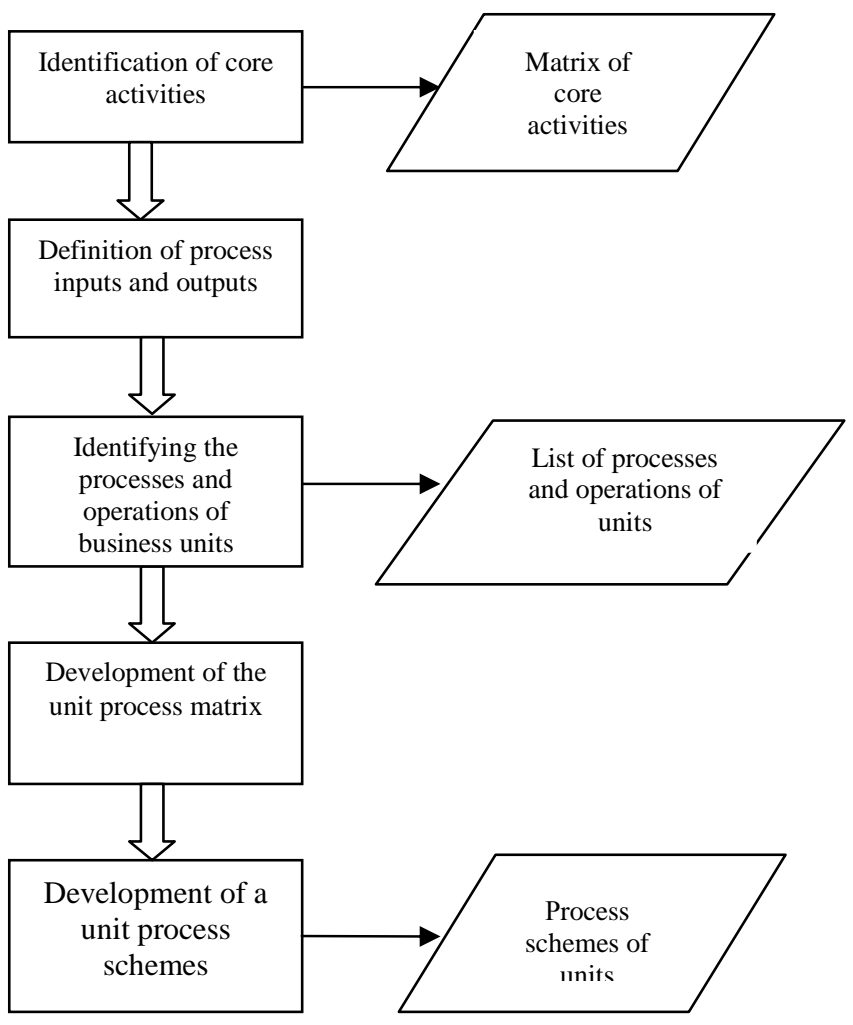

Fig. 6. Algorithm for determining the processes of the sub-unit of the organization

Block 2. The received information on the activities of the unit is analyzed on the basis of mathematical-statistical methods. One of the most effective methods of analyzing the company's business processes is the creation of Shewhart control cards. This method is aimed at identifying not only the quantitative indicators characterizing the structural characteristics of the process, but also the permissible (upper and lower) values of the process indicators and its nominal (target) value for determining the stability and reproducibility of the business process.

The purpose of Shewhart's control charts is to detect unnatural changes in data from repetitive processes and to provide criteria for detecting the absence of statistical controllability. The process is in a statistically manageable 
state, if variability is caused only by random factors. In determining this acceptable level of variability, any deviation from it is considered the result of the action of special causes that should be identified, excluded or weakened.

Let's consider an example of building a control chart of Shewhart. For this we suggest using MSExcel.

The first stage is the holding of timekeeping and the receipt of chronographs.

The second stage is the determination of the mean values for each chronological order (Xsr)

The third stage is the calculation of the range of sample mean deviations $\mathrm{R}$, which is calculated as the difference between the largest and the smallest values in the subgroup. The obtained data is recorded in a table (Table 2)

TABLE II. PRIMARY DATA FOR THE CONSTRUCTION OF SHEWHART'S MAP

\begin{tabular}{|c|c|c|c|c|c|}
\hline \multirow{2}{*}{$\begin{array}{c}\begin{array}{c}\text { Metering } \\
\text { No. }\end{array} \\
1 \\
\end{array}$} & \multicolumn{3}{|c|}{ Results of measurements } & \multirow{2}{*}{$\begin{array}{c}\text { Хср } \\
41,66667\end{array}$} & \multirow{2}{*}{$\begin{array}{r}\mathbf{R} \\
15 \\
\end{array}$} \\
\hline & 35 & 40 & 50 & & \\
\hline 2 & 50 & 60 & 75 & 61,66667 & 25 \\
\hline 3 & 89 & 97 & 99 & 95 & 10 \\
\hline 4 & 57 & 67 & 63 & 62,33333 & 10 \\
\hline 5 & 54 & 56 & 58 & 56 & 4 \\
\hline 6 & 98 & 99 & 97 & 98 & 2 \\
\hline 7 & 64 & 61 & 53 & 59,33333 & 11 \\
\hline 8 & 87 & 89 & 94 & 90 & 7 \\
\hline 9 & 99 & 83 & 95 & 92,33333 & 16 \\
\hline 10 & 45 & 58 & 61 & 54,66667 & 16 \\
\hline
\end{tabular}

Next, it is necessary to determine the boundaries in which the fluctuations in values can be considered "normal". For this we use GOST 50779.42-99 "Statistical methods. Control charts Shewhart ", which presents formulas for the calculation of the upper and lower control boundaries of the process, as well as the process sigma (central line)

The definition of the upper control limit of the process (Upper Control Limit.) Occurs in accordance with the following formula: $\mathrm{UCL}=\mathrm{X}+\mathrm{A} 2 * \mathrm{Rsp}$

The definition of the lower control limit of the process (Low Control Limit) - LCL $=\mathrm{X}-\mathrm{A} 2 * \mathrm{Rsp}$

A2 is a special engineering factor, the value of which is determined using the table of values of this variable. The table is given in the standard GOST 50779.42-99. The specific value of the variable depends on the amount of data in the subgroup. In our case, in subgroup 3, the values, therefore $\mathrm{A}=1,732$.

Rsp is the average range. It represents the difference between the largest and the smallest value of the swings in a subgroup.

$\mathrm{X}$ - the arithmetic mean of the arithmetic mean by the number of indicators. $X$ is the average for each subgroup, and then the average for all subgroups in general. $\mathrm{X}$ is also an average line equidistant from the upper and lower bounds of the "admissible values".

Thus, $\mathrm{X}=71.1, \mathrm{R}=11.6, \mathrm{~A}=1.732 . \mathrm{UCL}=91,2 \mathrm{LCL}$ $=51$. Based on this data, we construct the Shewhart map (Fig. 7),

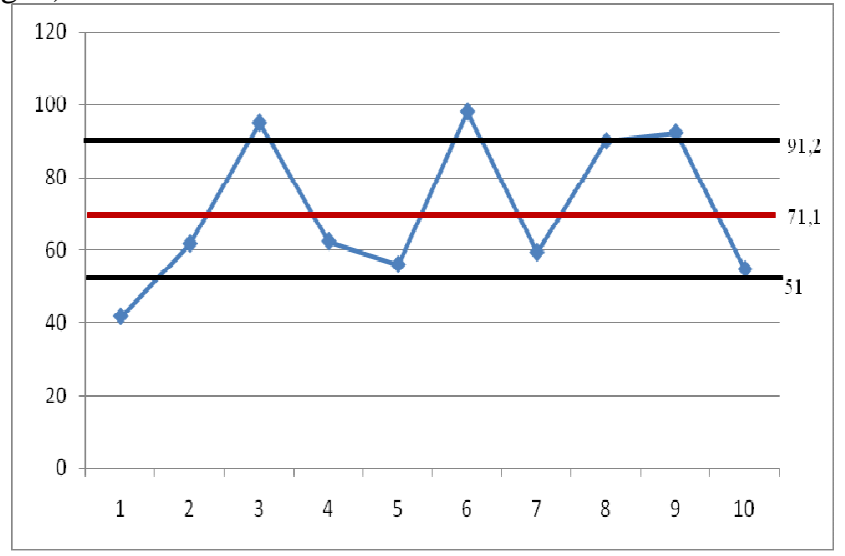

Fig.7. Shewhart's control chart

Analyzing the obtained deviations, we found out that outside the "normal distribution" came the values of measurements 3,6 and 9. Thus, at these points, there were abnormal deviations from the normal distribution of the process indices. Therefore, when building a business process diagram, it is necessary to analyze the deviations obtained and to find out the reasons for their occurrence.

Next, schemes are developed for the business processes of the unit. A simplified version of the business process description scheme is shown in Figure 8.

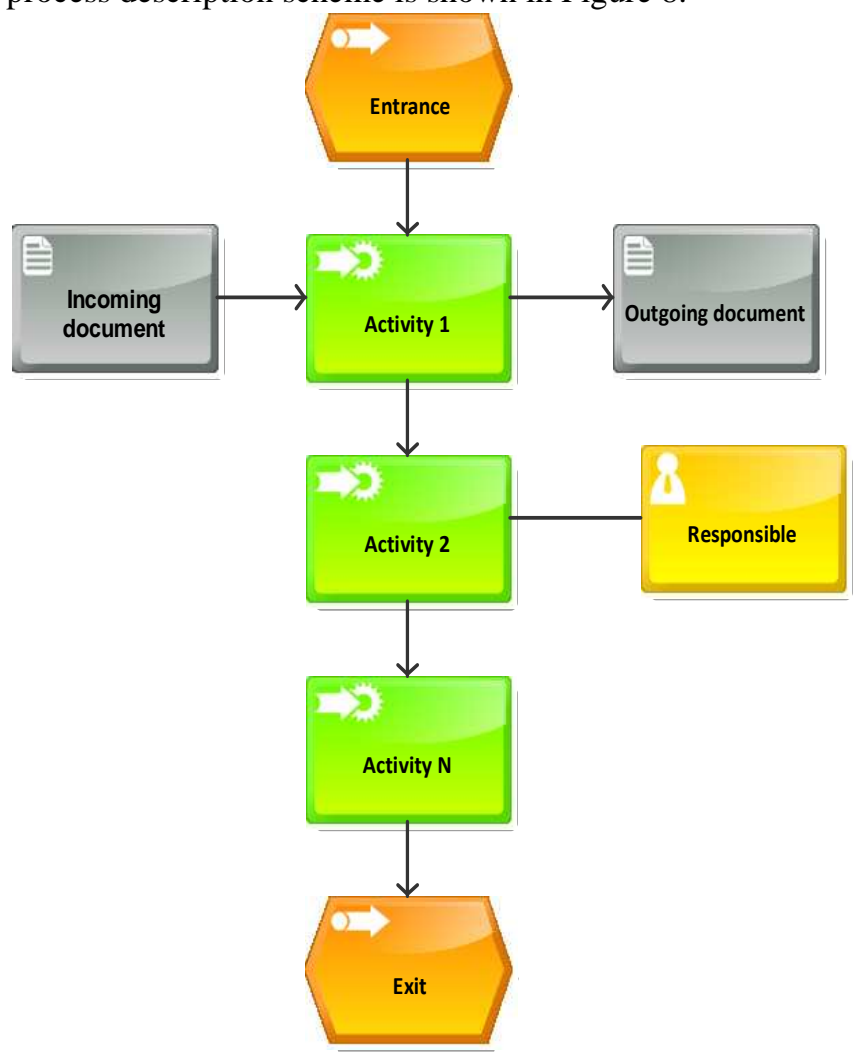

Fig.8. Scheme of business process description 
Block 3. Creating a structure of normative and methodical documentation. At this stage, what types of documents are defined and at what level they will be used to regulate activities, and the basic forms of documents (templates) are agreed and approved. In addition to the types of regulations presented in Figure 1, the procedure for the execution of the process can be further developed; documented procedure; operational process map and other documents, depending on the level of process regulation;

Block 4. Determination of the level of the regulated process and, in accordance with this, the choice of the type and form of the necessary regulations. Initially, it is necessary to determine the level of management and the corresponding type of regulation (see Figure 1). Further, the structure of the regulations is developed. We have developed unified structures of business process regulations and regulations-functions. Let us consider them in more detail.

The unified form of the business process regulation includes the following mandatory sections:

1. Title page

2. Content, including pages

3. General provisions. This section indicates the purpose of developing regulations, the scope of application, which functions and processes are regulated. Also, the employees who are to be guided by them in the performance of their activities are indicated, the main terms and definitions, as well as the regulatory legal acts that are used in the regulations, are given.

\subsection{Purpose and Scope}

3.2. Abbreviations used

3.3. Terms and definitions. A list of terms is developed taking into account the level of the document and the specifics of the activities of a specific company.

3.4. List of regulatory documents used to write the document. They can be both internal (local legal documents of the company) and external (laws, GOSTs, ISO, etc.)

4. General description of the process. This section describes the main stages of the process, as well as the participants and the distribution of responsibilities, the sequence of work. The most detailed regulations specify incoming and outgoing information and material flows, the timing of the work, events, inputs and outputs of the process, the frequency of the function, the maximum allowable costs and standards.

4.1. Initiation of the process - a description of the conditions for the start of the process

4.2. Description of the process (textual) with the sequence of work execution

4.3. Description of incoming and outgoing information and material flows

4.4. Subdivisions and officials participating in the business process with an indication of the distribution of responsibility

4.5. Process execution time

4.6. Process result

5. Graphical description of the process

6. Description of the operations of the process
7. Methods for monitoring the implementation of the process. In this section of the regulation it is prescribed who will monitor the implementation of this regulation and what is the responsibility of the persons for their non-compliance. In other words, the sanction of violation of the regulations is indicated here. Criteria for the effectiveness of the process can also be indicated here.

8. Final provisions. Reflect the procedure for making changes in the situation - how often should the rules be revised, who initiates the change, who agrees who makes it and who approves it.

The procedure is a document of the lower level of management that regulates the sequence of the implementation of the business process part and the interaction of the most responsible executors. The unified form of the procedure procedure procedure procedure is similar to the structure of the business process regulation and includes the following mandatory sections:

1. General Provisions

1.1. Purpose - general information about the document, regulated scope of activities.

1.2. Application area.

1.3. Normative references - a list of top-level documents.

1.4. Terms and Definitions.

2. General description of the procedure and conditions of implementation

2.1. Conditions of the beginning - the events initiating the execution of the procedure, the input data.

2.2. Description of the procedure (textual) with the sequence of work execution

2.2. Termination conditions-outputs of the procedure and its final results.

2.4. Participants in the procedure and responsible persons.

3. Graphical description of actions (procedure diagram)

4. Control of the implementation of the procedure, responsibility.

5. Final provisions.

The proposed unified document structures may vary depending on the type of process and the level of management.

Block 5. Development of regulations in accordance with the scheme: description of the procedure entry, description of the procedure itself and description of the procedure exit.

Block 6. Constant monitoring and, depending on its results, updating of the developed regulations. In order for business processes to work effectively, they need constant monitoring and updating of regulatory documentation. Monitoring of regulations of business processes of the organization is implemented according to the following scheme:

1. Collect information and analyze current business processes. To monitor the selected business processes, we propose to measure the costs of working hours or analyze the resources actually received at the output of the process. To determine the time costs, it seems to us possible to use such methods as: a photo of working hours, timing or method of moment observations, depending on the features of the activity being analyzed. 
2. Construction of Shewhart's charts based on the obtained statistical data.

3. Analysis of the obtained Shewhart's charts, identification of those indicators that go beyond the boundaries of the "normal" distribution and determine the causes of these deviations.

4. Correction of schemes and regulations of business processes in accordance with identified shortcomings.

The introduction of the regulation of the company's business processes will allow the company to achieve a number of both financial and non-financial results. The financial and production effectiveness of the introduction of business process regulation will be as follows:

1). Increase the productivity of staff through clear regulation of activities, lack of duplication of authority and non-productive work. According to experts, the proposed measures will increase the labor productivity of the personnel department staff by $20 \%$. Calculation of the effect of increasing labor productivity is proposed by the following formula:

$$
\mathrm{Ep}=\mathrm{R} * \mathrm{Dn} *(\mathrm{P} 2-\mathrm{P} 1)
$$

$\mathrm{R}$ - number of employees in the unit

Dn - number of working days in the calculated gap

P1-labor productivity before the introduction of activities

P1-labor productivity after implementation of activities

2 ). By optimizing the realized business processes in the personnel department, there will be savings from reducing losses of working time and unproductive expenses, determined by the following formula:

$$
\mathrm{Pt}=(\mathrm{B} * \mathrm{H} * \mathrm{~F}) * \mathrm{~S}
$$

$\mathrm{Pt}$ - economy due to reduction of losses of working time, rubles;

$\mathrm{B}$ - reduced losses and unproductive time during the working day, h;

$\mathrm{H}$ - the number of employees who reduced losses and unproductive costs, people;

$\mathrm{F}$ - annual fund of working hours of one management employee, days;

$\mathrm{S}$ - the average annual cost of one person-hour of an employee, rubles.

The formula for calculating the cost per man-hour of one employee is as follows:

$$
\mathrm{U}=\mathrm{ZP} / \mathrm{RF}
$$

$\mathrm{U}$ - the cost per man-hour;

$\mathrm{ZP}$ - wages of one employee per month (net);

$\mathrm{RF}$ - the number of working hours per month.

3 ). Reducing the complexity of processing information, defined by the formula:

$$
\mathrm{Pt}=\left(\mathrm{T}_{1}-\mathrm{T}_{2}\right) \cdot \mathrm{C}
$$

T1, T2 - the complexity of the procedure (operation) before and after the implementation of improvement measures;
$\mathrm{C}$ - the average annual cost of one person.

Organizational effectiveness is as follows:

- Improvement of functional interactions in units and between them,

- Ensuring the organization's ability to rebuild its structures, depending on changing objectives and the external environment

- Ensuring decision-making with clear and clear presentation

- Clear allocation of rights and responsibilities

- described and regulated business processes formalize the existing business model, eliminate duplication of functions.

1. Social effectiveness will be as follows:

- Due to a clear structure of the process and distribution of responsibilities, which also reduces the number of organizational conflicts.

- Employees, knowing that the processes are monitored, perform their work more conscientiously, which also affects the motivation of staff to work

- Accelerate the process of training new employees, due to a clear description of the requirements and schemes of interactions.

- Understanding of the final results of processes and on their basis the possibility of constructing a more effective employee incentive system.

Thus, based on the results of the introduction of the model for describing and regulating the business processes of the company, the following results will be obtained: a list of the described business processes in the field of personnel management; regulating scheme of interactions in the personnel management system; regulatory and legal documents that regulate the regulation of personnel; official regulations of the company's employees; improvement of performance indicators of personnel management (productivity growth, motivation increase)

\section{References}

[1] J.Jeston, J.Nelis, Management by Process: A Practical Road-mapto Sustainable Business Process Management, 2016.

[2] Zh.Yu. Dankova, Zh.N. Avilova, L.A. Minaeva, "Knowledge-based innovation system as a key factor for socio-economic development of the region," International Journal of Pharmacy \& Technology, Sep. Vol. 8, Issue №4, pp. 24699-24707, 2016.

[3] Yu.A. Doroshenko , A.A. Klimashevskaya, "Analysis of scientific and technical potential of enterprises of industry of building materials in the contex of estimation of necessity of carrying out of technological moderniation in the industry," Bulletin of BSTU named after V.G. Shukhov, no. 1, pp. 214-218. DOI: 10.12737/23532, 2017

[4] B. Andersen, Business processes: tools for improvement, Moscow: Alpina, 2015.

[5] M. Hammer, D. Champi, Reengineering of the corporation. Manifesto of the revolution in business, Moscow: Mann, Ivanov and Ferber, 2016

[6] V.V. Repin Process approach to management. Modeling of business processes, Moscow: Mann, Ivanov and Ferber, 2012.

[7] K. Jiang, D.P. Lepak, J.Hu, J.C.Baer How does human resource management influence organizational outcomes? A meta-analytic investigation of mediating mechanisms. Academy of management

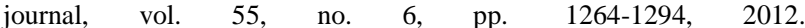
DOI: 10.5465/amj.2011.0088

[8] M .Kaneva, G. Untura Innovation indicators and regional growth in Russia. Economic change and restructuring, vol. 50, no. 2, pp. 133 159, 2017. DOI: 10.1007/s10644-016-9184-Z 